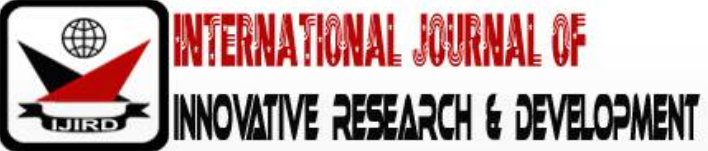

ISSN 2278-0211 (Online)

\section{Carbon Content Effects on the Heat Affected Zone Harden Ability of Tungsten Inert Gas Mild Steelwelds}

\author{
Standfast Apaemi \\ Engineer, Department of Production Engineering, University of Benin, Nigeria \\ Joseph Achebo \\ Professor, Department of Production Engineering, University of Benin, Nigeria \\ Dr. Andrew Ozigagun \\ Lecturer, Department of Production Engineering, University of Benin, Nigeria
}

\begin{abstract}
:
The weldability, strength and microstructural configuration of mild steel welds is determined by the carbon content composition of the weldment. In this study, the effects of carbon content on the hardness of the heat affected zone of mild steel welds has been investigated. A gas tungsten arc welding process was employed to weld the joints of the mild steel samples, thereafter data on carbon content and hardness was recorded. A data compatibility and suitability test criteria was done using the sequential sum of square and the analysis of variance (ANOVA). This rest indicated that welding has the most significant effect on the carbon content and hardness, combined interactive effects between the target response, current, voltage and gas flow rate.
\end{abstract}

Keywords: Carbon content, hardenability, mild Steel, heat affected zone, Tungsten Inert Gas, Welding

\section{Introduction}

The improvement of weld quality has been the main interest of most welding researchers today, a good weld must possess adequate strength greater than that of the parent materials and this can be achieved by optimizing the input parameters during the welding process. The contact between input and output process parameters determines the veracity of a weld. The HAZ, bead geometry, distortion, dilution and the thermal conductivity can be found out through this. If the carbon content can be reduced, it will improve the weldability and decrease the susceptibility. Boron additions commonly used to preserve hardenability [1]. If beyond the HAZ, material cracking happens it gives a good creep strength[2].

The heat affected zone (HAZ) estimation helps to find the accuracy level and the extent of occurrence without the need for many costly and time-consuming process [3]. It is very essential to have a knowledge about whole area and of subareas of the HAZ [4]. Prior austenite grain sizes on hardenability helps to predict the HAZ hardness. For 400 to $490 \mathrm{MPa}$ grade steels the prediction is easy [5]. HAZ represents a zone where some structural changes in the welded material occurred [6]. The IC GC HAZ in the steels van be received from a combination of Scanning Electron Microscopy (SEM) and Image Analysis of the resultant SEM micrographs [7].The result obtained from actual welds can be further confirmed through weld thermal cycle simulation[8].

The quality can be improved through the welding process optimization [9].The future estimation of the weld pool geometry has been evaluated through the artificial neural network[10]. Further, Response Surface Methodology (RSM), can be used for improving and optimizing processes. RSM also provides relationships among one or more measured responses and the vital input factors[11].The fractional factorial model can be used to forecast the bead geometry or to establish a grouping or a range of parameters to obtain the desired bead geometry dimensions inside the factors area [12]. It was found that the fractional factorial technique was suitable for the forecasting the main effects and the interaction effects of different combinations of welding parameters[13].

\section{Research Methodology}

\subsection{Design of Experiment}

For maximizing as well as minimizing the responses of the manufacturing process, design of experiment is very popular. This study considers many factors like welding current, gas flow rate, and voltage. The central composite design has been adopted here. Three principles of the experimental design, i.e. rules of repetition, randomization and local control have been followed here. The below mentioned table indicates the input factors. 


\begin{tabular}{|c|c|c|c|c|}
\hline Parameters & Unit & Symbol & $\begin{array}{c}\text { Coded } \\
\text { value }\end{array}$ & $\begin{array}{c}\text { Coded } \\
\text { value }\end{array}$ \\
\hline & & & Low(-1) & High(+1) \\
\hline Current & Amp & A & 110 & 150 \\
\hline Gas flow rate & Lit/min & F & 25 & 28 \\
\hline Voltage & Volt & V & 11 & 15 \\
\hline
\end{tabular}

Table 1: Process Factors and Their Range

\begin{tabular}{|c|c|c|c|c|c|c|}
\hline Std & Run & Current & Voltage & Gas flow & CC & Hardness \\
\hline 11 & 1 & 150.23 & 26.5 & 12.5 & 1.1 & 367 \\
\hline 3 & 2 & 125 & 26.5 & 12.5 & 5.2 & 200 \\
\hline 17 & 3 & 125 & 26.5 & 12.5 & 5.4 & 193 \\
\hline 20 & 4 & 125 & 26.5 & 12.5 & 5.6 & 195 \\
\hline 14 & 5 & 140 & 25 & 11 & 5 & 225 \\
\hline 10 & 6 & 125 & 23.98 & 12.5 & 6 & 165 \\
\hline 9 & 7 & 140 & 25 & 14 & 4.5 & 272 \\
\hline 1 & 8 & 125 & 26.5 & 15.02 & 6.7 & 270 \\
\hline 8 & 9 & 140 & 28 & 11 & 4.2 & 300 \\
\hline 12 & 10 & 110 & 25 & 14 & 4.9 & 262 \\
\hline 16 & 11 & 125 & 29.02 & 12.5 & 5.7 & 220 \\
\hline 13 & 12 & 125 & 26.5 & 12.5 & 5.7 & 219 \\
\hline 4 & 13 & 125 & 26.5 & 9.98 & 6.2 & 191 \\
\hline 2 & 14 & 110 & 25 & 11 & 4.8 & 209 \\
\hline 19 & 15 & 99.77 & 26.5 & 12.5 & 4.3 & 266 \\
\hline 15 & 16 & 125 & 26.5 & 12.5 & 4.8 & 230 \\
\hline 7 & 17 & 140 & 28 & 14 & 3.25 & 267 \\
\hline 5 & 18 & 125 & 26.5 & 12.5 & 5 & 229 \\
\hline 6 & 19 & 110 & 28 & 11 & 6.23 & 230 \\
\hline 18 & 20 & 110 & 28 & 14 & 6.35 & 226 \\
\hline
\end{tabular}

Table 2: Experimental Results

\subsection{Experimental Procedure}

Mild steel plates of $10 \mathrm{~mm}$ thickness were cut into rectangular pieces measuring $60 \times 40 \mathrm{~mm}$ using a hacksaw and coolant. Proper cleaning need to done to ensure a sound weld. Heat generated was minimized to avoid changes in the microstructure. TIG welding machine was appropriately calibrated to the desired amperage and voltage. A single bead can ensure uniform fusion of the plates. The weld was de-slagged, washed and welded again. After the final welding process a grinding machine has been employed to clean the weld. The specimen was allowed to cool before the carbon content and hardness was determined.

\subsection{Materials Used for the Experiment}

Mild steel is very popular as it is easily available and cost-effective. Almost every product is being created from steel. Wielding can be easily done on the steel. It is very durable also. Steel generally contains less than $2 \%$ carbon. Due to its in expensive nature, it can be hugely used. 


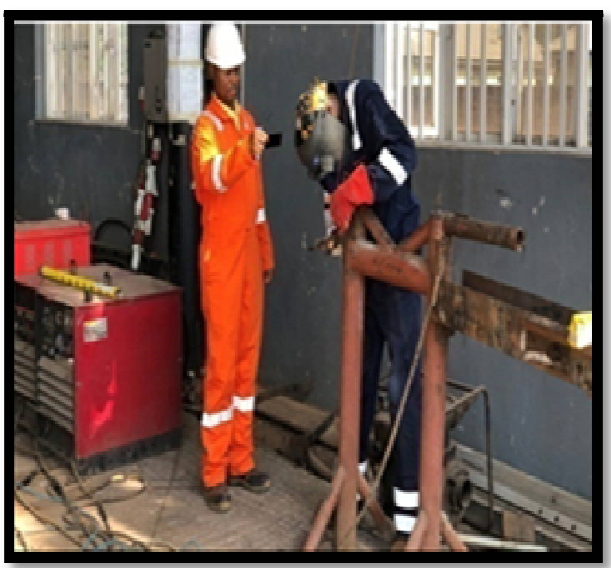

Figure 1: TIG Welding Machine

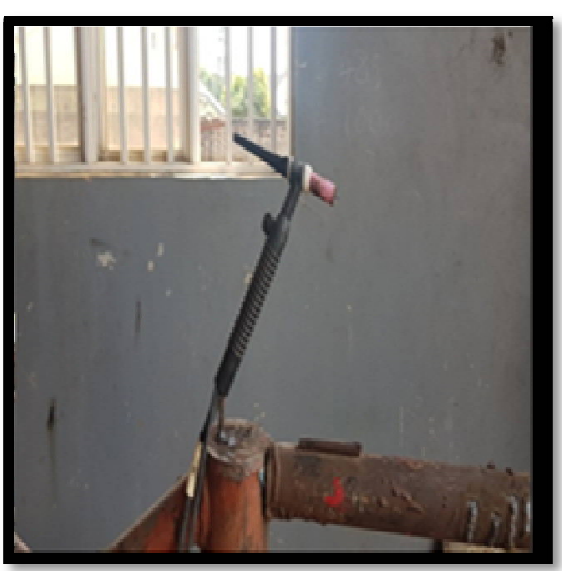

Figure 2: TIG Welding Torch

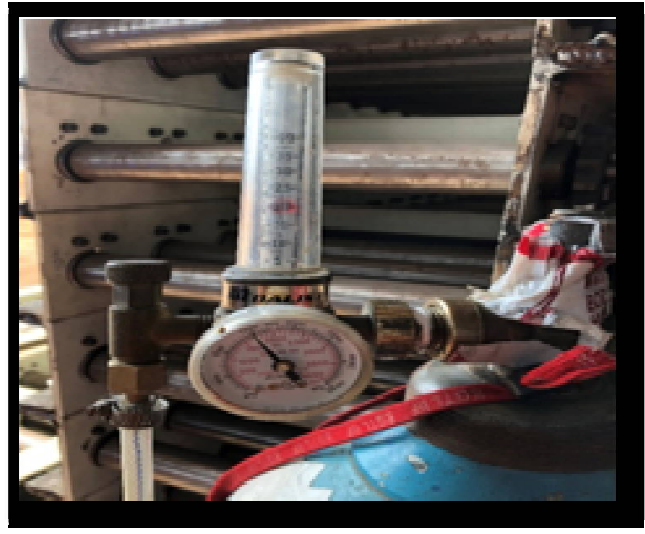

Figure 3: Shielding Gas Cylinder and Regulator

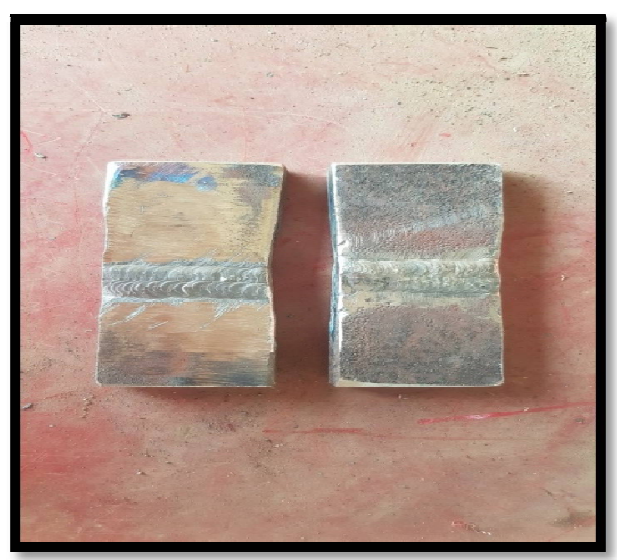

Figure 4: Welded Sample 


\section{Results and Discussion}

In assessing the strength of the quadratic model towards minimize the carbon content one way analysis of variance (ANOVA) table was generated which is presented in Table 3

\begin{tabular}{|c|c|c|c|c|c|c|}
\hline & Sum of & & Mean & F & p-value & \\
\hline Source & Squares & Df & Square & Value & Prob> F & \\
\hline Model & 28.55 & 9 & 3.17 & 23.47 & $<0.0001$ & Significant \\
\hline A-current & 8.40 & 1 & 8.40 & 62.16 & $<0.0001$ & \\
\hline B-voltage & $7.756 \mathrm{E}-003$ & 1 & $7.756 \mathrm{E}-003$ & 0.057 & 0.8155 & \\
\hline C-gas flow rate & 0.011 & 1 & 0.011 & 0.082 & 0.7804 & \\
\hline $\mathrm{AB}$ & 3.04 & 1 & 3.04 & 22.48 & 0.0008 & \\
\hline $\mathrm{AC}$ & 0.35 & 1 & 0.35 & 2.58 & 0.1394 & \\
\hline $\mathrm{BC}$ & 0.023 & 1 & 0.023 & 0.17 & 0.6880 & \\
\hline $\mathrm{A}^{\wedge} 2$ & 12.47 & 1 & 12.47 & 92.22 & $<0.0001$ & \\
\hline $\mathrm{B}^{\wedge} 2$ & 0.49 & 1 & 0.49 & 3.60 & 0.0871 & \\
\hline $\mathrm{C}^{\wedge} 2$ & 2.26 & 1 & 2.26 & 16.70 & 0.0022 & \\
\hline Residual & 1.35 & 10 & 0.14 & & & not \\
\hline Lack of Fit & 0.74 & 5 & 0.15 & 1.22 & 0.4156 & significant \\
\hline Pure Error & 0.61 & 5 & 0.12 & & & \\
\hline Cor Total & 29.90 & 19 & & & & \\
\hline
\end{tabular}

Table 3: ANOVA Table for Carbon Content

To validate the adequacy of the quadratic model based on its ability to minimize carbon content the goodness of fit statistics is presented in table 3.2

\begin{tabular}{|c|c|c|c|}
\hline Std. Dev. & $\mathbf{0 . 3 7}$ & R-Squared & $\mathbf{0 . 9 5 4 8}$ \\
\hline Mean & 5.05 & Adj R-Squared & 0.9141 \\
\hline C.V. $\%$ & 7.29 & Pred R-Squared & 0.7805 \\
\hline PRESS & 6.56 & Adeq Precision & 19.810 \\
\hline
\end{tabular}

Table 4: Goodness of Fit Statistics for Carbon Content

To obtain the optimal solution, we first consider the coefficient statistics and the corresponding standard errors. The computed standard error measures the difference between the experimental terms and the corresponding predicted terms. Coefficient statistics for carbon content response variable is presented in Table 5

\begin{tabular}{|c|c|c|c|c|c|c|}
\hline & Coefficient & & Standard & $\mathbf{9 5 \%}$ CI & $\mathbf{9 5 \%}$ CI & \\
\hline Intercept & 5.29 & 1 & 0.15 & 4.95 & 5.62 & -0.56 \\
\hline A-current & -0.78 & 1 & 0.099 & -1.01 & 1.00 \\
\hline B-voltage & 0.024 & 1 & 0.099 & -0.20 & 0.25 & 1.00 \\
\hline C-gas flow rate & -0.028 & 1 & 0.099 & -0.25 & 0.19 & 1.00 \\
\hline $\mathrm{AB}$ & -0.62 & 1 & 0.13 & -0.91 & -0.33 & 1.00 \\
\hline $\mathrm{AC}$ & -0.21 & 1 & 0.13 & -0.50 & 0.081 & 1.00 \\
\hline $\mathrm{BC}$ & -0.054 & 1 & 0.13 & -0.34 & 0.24 & 1.00 \\
\hline $\mathrm{A}^{\wedge} 2$ & -0.93 & 1 & 0.097 & -1.15 & -0.71 & 1.02 \\
\hline $\mathrm{B}^{\wedge} 2$ & 0.18 & 1 & 0.097 & -0.032 & 0.40 & 1.02 \\
\hline $\mathrm{C}^{\wedge} 2$ & 0.40 & 1 & 0.097 & 0.18 & 0.61 & 1.02 \\
\hline
\end{tabular}

Table 5: Coefficient Estimates Statistics Generated for Carbon Content

The optimal equation which shows the individual effects and combine interactions of the selected input variables (current, voltage and gas flow rate) against the mesured carbon content is presented based on the actual values in Table 6 


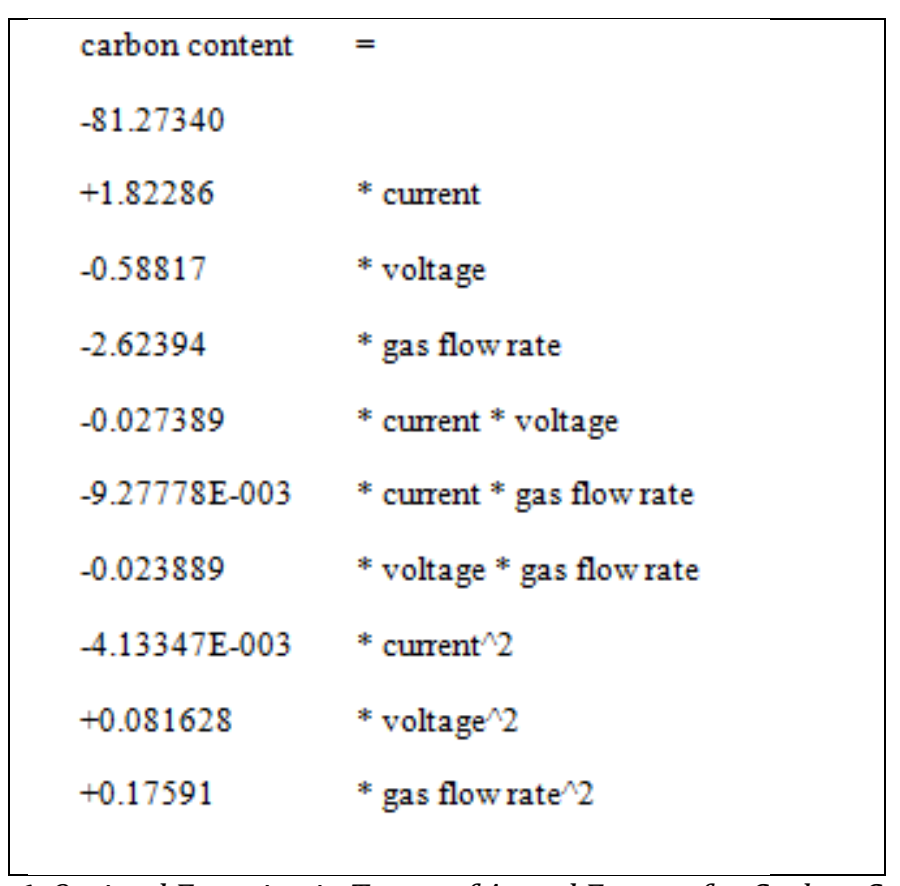

Table 6: Optimal Equation in Terms of Actual Factors for Carbon Content

The diagnostics case statistics which shows the observed values of carbon content against their predicted values is presented in Table 7 . The diagnostic case statistics actually give insight into the model strength and the adequacy of the optimal second order polynomial equation.

\begin{tabular}{|c|c|c|c|c|c|c|c|c|c|}
\hline & & & & & Internally & Externally & $\begin{array}{c}\text { Influence } \\
\text { on }\end{array}$ & & \\
\hline Standard & Actual & Predicted & & & Studentized & Studentized & $\begin{array}{l}\text { Fitted } \\
\text { Value }\end{array}$ & Cook's & Run \\
\hline Order & Value & Value & Residual & Leverage & Residual & Residual & DFFITS & Distance & Order \\
\hline 1 & 4.80 & 4.85 & -0.046 & 0.670 & -0.216 & -0.205 & -0.292 & 0.009 & 14 \\
\hline 2 & 5.00 & 4.93 & 0.073 & 0.670 & 0.346 & 0.330 & 0.470 & 0.024 & 5 \\
\hline 3 & 6.23 & 6.23 & $\begin{array}{c}-3.235 \mathrm{E}- \\
003\end{array}$ & 0.670 & -0.015 & -0.015 & -0.021 & 0.000 & 19 \\
\hline 4 & 4.20 & 3.85 & 0.35 & 0.670 & 1.659 & 1.848 & $* 2.63$ & 0.558 & 9 \\
\hline 5 & 4.90 & 5.31 & -0.41 & 0.670 & -1.958 & -2.365 & $*-3.37$ & 0.777 & 10 \\
\hline 6 & 4.50 & 4.56 & -0.060 & 0.670 & -0.283 & -0.270 & -0.385 & 0.016 & 7 \\
\hline 7 & 6.35 & 6.49 & -0.14 & 0.670 & -0.645 & -0.625 & -0.890 & 0.084 & 20 \\
\hline 8 & 3.25 & 3.27 & -0.018 & 0.670 & -0.083 & -0.079 & -0.112 & 0.001 & 17 \\
\hline 9 & 4.30 & 3.97 & 0.33 & 0.607 & 1.413 & 1.498 & 1.863 & 0.309 & 15 \\
\hline 10 & 1.10 & 1.34 & -0.24 & 0.607 & -1.025 & -1.028 & -1.279 & 0.163 & 1 \\
\hline 11 & 6.00 & 5.77 & 0.23 & 0.607 & 1.019 & 1.021 & 1.270 & 0.161 & 6 \\
\hline 12 & 5.70 & 5.85 & -0.15 & 0.607 & -0.631 & -0.611 & -0.760 & 0.062 & 11 \\
\hline 13 & 6.20 & 6.45 & -0.25 & 0.607 & -1.099 & -1.112 & -1.383 & 0.187 & 13 \\
\hline 14 & 6.70 & 6.36 & 0.34 & 0.607 & 1.487 & 1.598 & 1.988 & 0.342 & 8 \\
\hline 15 & 5.20 & 5.29 & -0.086 & 0.166 & -0.256 & -0.244 & -0.109 & 0.001 & 2 \\
\hline 16 & 5.00 & 5.29 & -0.29 & 0.166 & -0.852 & -0.839 & -0.375 & 0.014 & 18 \\
\hline 17 & 5.60 & 5.29 & 0.31 & 0.166 & 0.936 & 0.929 & 0.415 & 0.017 & 4 \\
\hline 18 & 5.70 & 5.29 & 0.41 & 0.166 & 1.234 & 1.271 & 0.568 & 0.030 & 12 \\
\hline 19 & 4.80 & 5.29 & -0.49 & 0.166 & -1.447 & -1.544 & -0.690 & 0.042 & 16 \\
\hline 20 & 5.40 & 5.29 & 0.11 & 0.166 & 0.340 & 0.324 & 0.145 & 0.002 & 3 \\
\hline
\end{tabular}

Table 7: Diagnostics Case Statistics Report of Observed Versus Predicted Carbon Content

To study the effects of combine input variables on the carbon content, 3D surface plots presented in Figure 5 was generated as follows: 


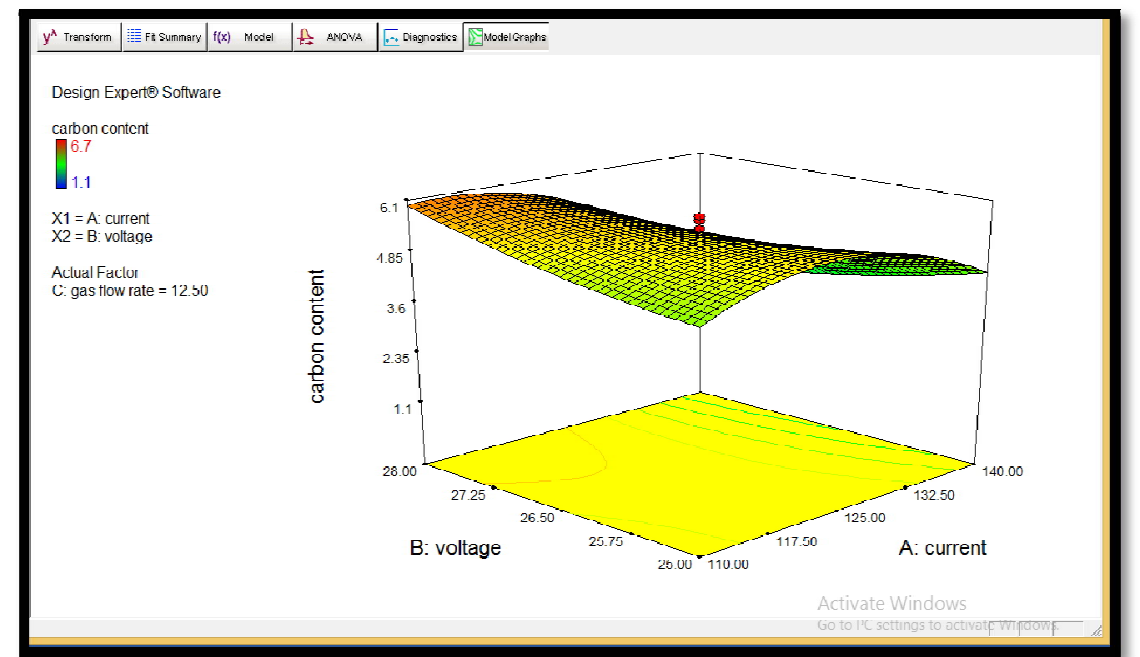

Figure 5: Effect Of Current and Voltage on Carbon Content

To study the effects of gas flow rate and current on the carbon content, 3D surface plots presented in Figure3.2 was generated as follows:

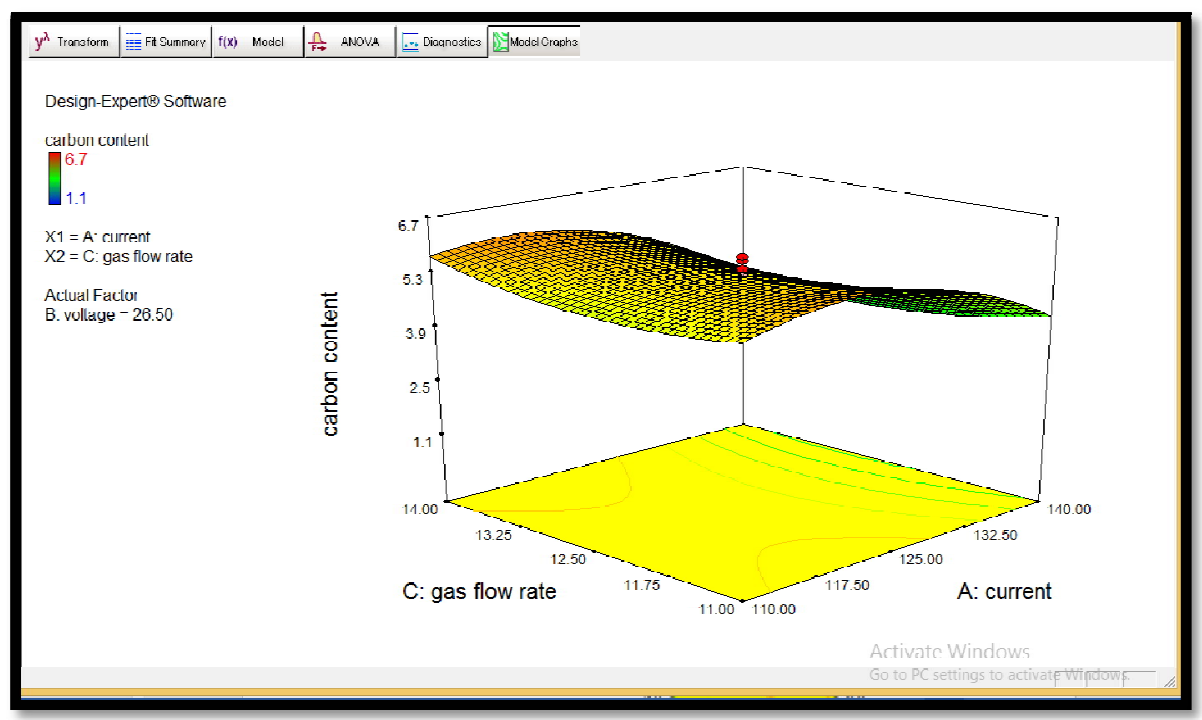

Figure 6: Effect of Current and Gas Flow Rate on Carbon Content

To study the effects of gas flow rate and voltage on the carbon content 3D surface plots presented in Figure 7 was generated as follows:

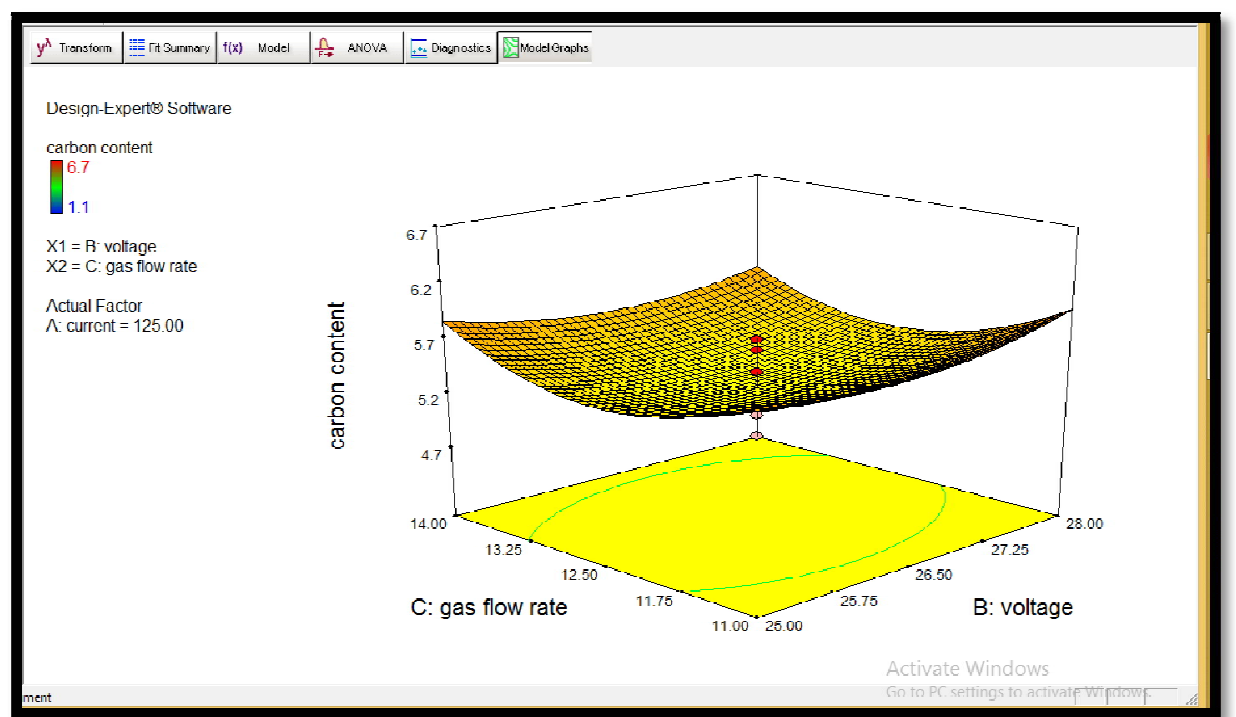

Figure 7: Effect of Voltage and Gas Flow Rate on Carbon Content 
The numerical optimization produces about fifteen (15) optimal solutions which are presented in table 3.6

\begin{tabular}{|c|c|c|c|c|c|}
\hline Number & Current & Voltage & Gas Flow Rate & $\begin{array}{l}\text { Carbon } \\
\text { Content }\end{array}$ & Hardness \\
\hline 1 & 140.00 & 28.00 & 11.00 & 3.84955 & 298.611 \\
\hline 2 & 140.00 & 27.99 & 11.00 & 3.8508 & 298.444 \\
\hline 3 & 140.00 & 28.00 & 11.02 & 3.83651 & 298.38 \\
\hline 4 & 139.83 & 28.00 & 11.00 & 3.88348 & 297.339 \\
\hline 5 & 140.00 & 27.96 & 11.00 & 3.85412 & 298.008 \\
\hline 6 & 139.69 & 28.00 & 11.00 & 3.91195 & 296.272 \\
\hline 7 & 139.38 & 28.00 & 11.00 & 3.97431 & 293.937 \\
\hline 8 & 140.00 & 27.87 & 11.00 & 3.86612 & 296.522 \\
\hline 9 & 140.00 & 28.00 & 11.22 & 3.70094 & 295.945 \\
\hline 10 & 138.49 & 28.00 & 11.00 & 4.14768 & 287.453 \\
\hline 11 & 140.00 & 27.50 & 11.00 & 3.92656 & 290.225 \\
\hline 12 & 140.00 & 25.23 & 14.00 & 4.40682 & 276.568 \\
\hline 13 & 140.00 & 25.24 & 14.00 & 4.39975 & 276.7 \\
\hline 14 & 140.00 & 25.35 & 14.00 & 4.33181 & 277.952 \\
\hline 15 & 139.95 & 25.21 & 14.00 & 4.42895 & 276.017 \\
\hline 16 & 139.96 & 25.12 & 14.00 & 4.48805 & 274.94 \\
\hline 17 & 140.00 & 25.46 & 14.00 & 4.26847 & 279.087 \\
\hline 18 & 139.90 & 25.40 & 14.00 & 4.32078 & 277.891 \\
\hline 19 & 140.00 & 28.00 & 11.66 & 3.45018 & 291.399 \\
\hline 20 & 140.00 & 25.46 & 13.93 & 4.24075 & 277.724 \\
\hline 21 & 139.90 & 26.28 & 14.00 & 3.84668 & 285.229 \\
\hline 22 & 140.00 & 26.48 & 14.00 & 3.74006 & 286.824 \\
\hline 23 & 139.43 & 27.30 & 14.00 & 3.55575 & 285.002 \\
\hline 24 & 140.00 & 25.79 & 12.79 & 3.86702 & 262.843 \\
\hline 25 & 110.00 & 25.00 & 14.00 & 5.31355 & 263.391 \\
\hline
\end{tabular}

From the results of table 3.6, it was observed that a current of 140 -amp, voltage of 28volt, and gas flow rate of $11.00 \mathrm{~L} / \mathrm{min}$ will result in a welding process with Carbon content of 3.84\%and hardness 298.

\section{Conclusion}

The effects of carbon content on the hardness of the heat affected zone of mild steel welds has been investigated in this paper. The result obtained shows that a second order quadratic polynomial can best explain the effect of the carbon content on the hardenability. A suitability test criterion was done by the analysis of variance, he ANOVA result shows that the current parameter has significant effect on the carbon content and hardness. The higher the current the lower the carbon content and the better the hardness value, the surface plots showed the combined interactive effects between the target response, current, voltage and gas flow rate. A final optimal solution of current of 140 -amp, voltage of $28 \mathrm{volt}$, and gas flow rate of $11.00 \mathrm{~L} / \mathrm{min}$ will result in a welding process with Carbon content of 3.84\%and hardness 298 was achieved.

\section{References}

i. D. P. Dunne: 'Ferrite morphology and residual phases in continuously cooled low carbon steels', Materials Forum, Phase Transformations in Engineering Materials, pub. by IMEA, 1999, 63-76.

ii. T. Jóźwik, (1998).'steelscr-mo-v for work at elevated temperatures after long-term operation problems of welding' [in Polish], Proceedings of 1-st scientific-technical conference Pire-98, isbn 83-909539-5-1, 69-80

iii. E.S. Dzidowski, J. Banach, (1998).' Working conditions and the potential damage of energy pipelines with respect to welding technology' [in Polish], Proceedings of 1-st scientific-technical conference Pire-98, isbn 83-909539-5-1, 57-62,

iv. E.S. Dzidowski, (1998).'criteria for assessing of the influence of technology of production and repairs on the properties of materials used in the construction of energy facilities '[in Polish], Proceedings of 1-st scientifictechnical conference Pire-98, isbn 83-909539-5-1, 51-56,

v. Tadashi KASUYAand Yuji HASHIBA (2007)' Carbon Equivalent to Assess Hardenability of Steel and Prediction of HAZ Hardness Distribution' NIPPON STEEL TECHNICAL REPORT No. 95 January 2007

vi. Z. Śloderbach and J. PaJąk(2015)' determInAtIOn OF rAnges OF cOmpOnents OF heAtAFFectedzOneIncludIngchAnges OF structure' ARCHIVES OF METALLURGY AND MATERIALS Volume 60 2015 Issue 4

vii. Y. LI, D. N. CROWTHER, M. J. W. GREEN, P. S. MITCHELL and T. N. BAKER(2001)' The Effect of Vanadium and Niobium on the Properties and Microstructure of the Intercritically Reheated Coarse Grained Heat Affected Zone in Low Carbon Microalloyed Steels' ISIJ International, Vol. 41 (2001), No. 1, pp. 46-55 
viii. W. Pang , N. Ahmed and. Dunne(2011)' Hardness and microstructural gradients in the heat affected zone of welded low-carbon quenched and tempered steels' Australasian Welding Journal, 56 (2), 36-48.

ix. UgurEsme, Melih Bayramoglu, Yugut Kazoncogul and SuedaOzgun, (2009), Optimization of weld bead geometry in TIG welding process using Gray relation analysis and Taguchi method, Materials and Technology, 43 PP 143149.

x. Juang SC, Tarng YS, Lii HR. A comparison between the back propagation and counter-propagation networks in the modelling of the TIG welding process. J Mater Process Technol 1998;75:54-62

xi. Palani. P.K., Saju M., 'Modelling and Optimization of Process Parameters for TIG Welding of Aluminium- 65032 Using Response Surface Methodology', International Journal of Engineering Research and Applications, Vol. 3, Issue 2, March -April 2013, pp.230-236

xii. Raveendra And R. S. Parmar, Mathematical Models To Predict Weld Bead Geometry For Flux Cored Arc Welding, J. Of Metal Construction, Vol. 19, N. 2, January 1987, Pp. 31r-35r

xiii. V. K. Gupta and R. S. Parmar, Fractional factorial technique to predict dimensions of the weld bead in automatic submerged arc welding, IE(I) Journal-MC, Vol. 70, Nov. 1989, pp.67-75. 